\title{
A stralegy for supporting faculty use of the Web
}

\author{
by Terese Heidenwolf and Jack Kayser
}

\section{Collaborative team provides coordinated support and more}

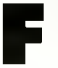

or the past three years, both the library and computing services at Lafayelte College have been facing a growing demand for training and support from faculty using the World Wide Web. Because demand has grown quickly, changes in the Web are so frequent, and no new staff has been added to service Web use, support and training have been ad hoc and sometimes ineffectual. To remedy this situation and encourage more faculty to use the Web, a collaborative strategy was developed for providing Web support and training at Lafayette, drawing upon expertise already available on campus.

\section{An integrated approach}

Librarians at Lafayette, along with others on campus, had been offering Web training for several years, but knew that faculty needed more support. While there were knowledgeable Web users scattered throughout campus, with a few faculty serving as unofficial experts in their departments, there was also frustration among some faculty that no unit on campus had formal responsibility for supporting Web use. Librarians wanted to see better coordination of campus Web support without relinquishing their role as key players in Web training. To this end, they decided to take the lead and form a team of Web trainers who would provide Web support and pool campus expertise

Librarians approached colleagues in other departments and drew together a team of com- puting services staff, librarians, and an educational technologies specialist. While members of the team represent only a small portion of campus Web experts, team members felt confident that they could be facilitators of Web support on campus. By taking formal responsibility for support, the team hoped to move toward a coordinated service, which could then draw upon the expertise of others when needed.

The team (dubbed "The Web Support. Team") quickly identified several goals it hoped to achieve beyond just answering faculty's questions about the Web. These goals included promoting faculty use of the Web, providing a forum where faculty with Web expertise could share their knowledge, and offering a range of instructional services for beginning through advanced Web users. To meet these goals, the team decided to offer a combination of workshops, on-demand support, and informal presentations during the noon hour.

Since Web workshops were being taught by various departments on campus with some duplication, the team consolidated what was already being done and developed a schedule of sequential workshops for people of varying knowledge levels. The schedule consists of four two-hour workshops taught on a regular basis: an introduction to the Web and Netscape ("Netscape for Beginners"), an introduction to creating Web pages ("Writing for the Web"), detailed instruction on digitizing and manipulating images ("Scanning for the Web"), and a class for Web authors who want to learn some advanced design techniques ("Beyond HTML"). The class for beginning writers is offered three times per year, while all the others are offered twice. Because most of these workshops-or 
at least portions of them-had already been taught in various forms, team members had only to combine some of their scripts and coordinate schedules to put the workshop component of their plan in place.

Although faculty are encouraged to attend the workshops, the team thought it also important to offer individual consultations for faculty who need additional help or who have questions that demand immediate attention. Despite some concerns about being overwhelmed with requests, the team decided to offer and advertise on-demand support to all faculty. This support ranges from answering simple questions over e-mail or the telephone to meeting with faculty in their offices to assist with browser configuration or page authoring. Although some faculty have been taking aclvantage of this service, the demand has not been too large to handle, and by distributing the workload, team members are able to provide on-demand support in a timely fashion without disrupting their other work.

\section{A forum for teaching and discussion}

Biweekly lunchtime presentations or "brown bags" are the final component of the team's offerings and are aimed at faculty who already have experience with the Web but who want to learn more or keep up with new developments. At each brown bag, one or two speakers present information on a Web-related topic for 20 to 30 minutes and then engage in a discussion with members of the audience. Team members made presentations at the two initial brown bags but then asked faculty in attendance or others knowledgealole about the Wels to speak on a topic of their choice at subsequent sessions. (See sidebar for a list of brown bag topics.)

These lunchtime presentations have been particularly successful. They seem to be the

\section{Brown bag topics}

- Loacling and using Acrobat Reader

- Techniques for searching the Web

- Using tables effectively

- Basics of scanning images for the Web

- Designing Web pages for teaching and professional use

- Extending class discussions with Web conferences

- Audio files on the Web ideal forum for teaching people about diverse topics that relate to the Web and for getting faculty members involved in the teaching. The informality of the brown bags and the short presentation time make it less daunting for faculty to volunteer to speak, while the frequency of the brown bags allows for the coverage of many small, discrete topics that might be hard to fashion into a coherent formal workshop.

In addition to being instructive, the brown hags have also been successful in providing a forum for discussing Web use on campus and for making more faculty aware of what their colleagues are doing. The discussions that follow each presentation have been lively and frequently wancler far from the topic being covered as faculty exchange ideas about how to use the Wel in class, tell one another about some new software they have discovered, or clescribe their latest projects. Fáculty who attend the brown bags because they are considering using the Web in teaching have a chance to solicit advice or ask for help. Team members and others from the library and computing services who listen to these discussions get a better understanding of how faculty are using the Web for instruction and what kind of support is most needed.

Because its work was well-received. the team decided to expand its offerings beyond the initial plan and gather more resources for Web users. Naturally enough, team members had built a Wel site where instructional materials as well as announcements of Web activities were mounted. (See www lafayette.edu/ library/support.) To supplement this and other materials available on the Web, the team purchased reference books for Web designers, which were added to the library collection and advertised on the team's Web site. One team member also started a campus bulletin board on Web topics to provide a place beyond brown bags where Wel discussions could occur. The team even extended its support to providing hardware by moving the library's scanner to a semipulalic area of the Reference Department and making it available to all faculty who want to digitize images for the Web.

\section{Measuring success}

Though there is more work for the Web Support Team to do, team members feel they have

(Facalty use cont. on page 566) 


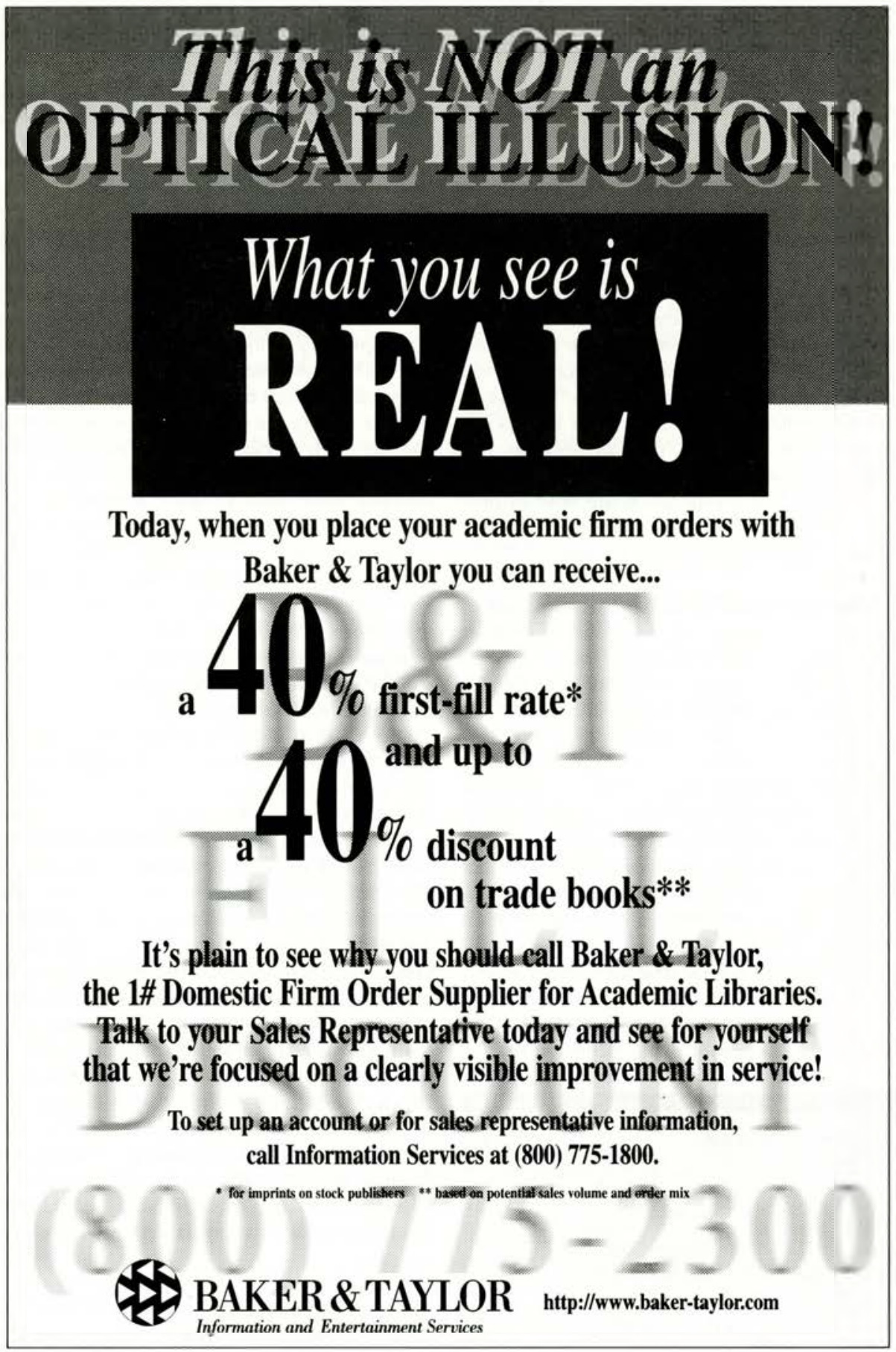


Banionyte, director of the Vilnius Pedagogical University Library. Banionyte spoke of and described the various cooperative efforts initiated by Lithuanian lilsraries after the declaration of that country's independence in 1990. She described a variety of cooperative endeavors between Lithuanian libraries and other libraries, especially those in Nordic countries. She identified the Lithuanian Librarians Association as being the most active group in Lithuania in creating and maintaining international contacts as well as carrying out general library development projects.

speaking to a problem that is common throughout the former Soviet Inion, Elena K. Aleksandrova of the National Parliamentary Library of Ukraine in Kiev spoke on "Ukrainian Libraries in the Legal Environment." Aleksandrova discussed the progress and clevelopment in Ukraine of a legal infrastructure appropriate for a relatively new independent state and indicated that some 900 separate legislative acts have been approved. Libraries in Ukraline are under the direct or indirect jurisdiction of some 20 different, recently enacted laws. In general. these laws ensure the rights of citizens to access information via libraries.

\section{PROVE Y OUR POINT}

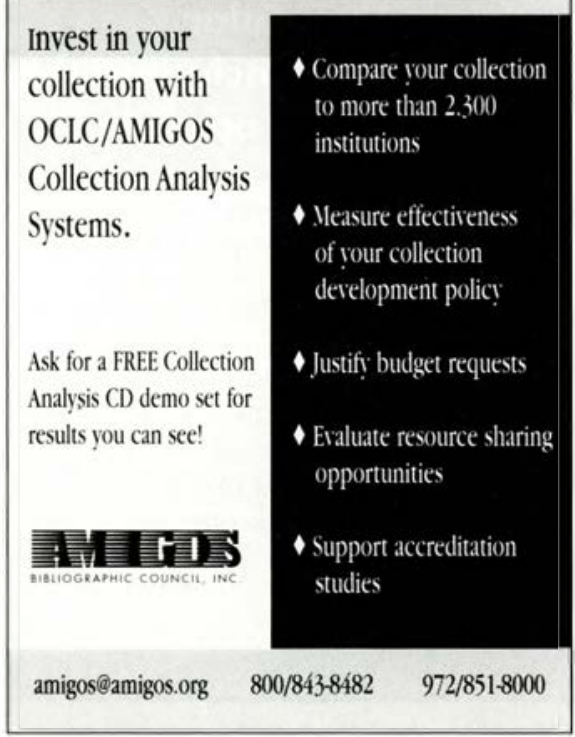

Nevertheless, there are a number of laws that seemingly allow for variant interpretation, and some aspects of library activities and services are not reflected in the approved legislation. Further, some executive aspects of the laws are in clispute. Aleksandrova also pointed out that current economic conditions in Ukraline often force unpopular decisions about libraries, including the reduction of their hours of operation, the transfer of library staff to parttime employment, and, in some cases, the closing of libraries.

The foregoing are but a few examples of the wide variety of presentations made at Crimea 97 about libraries and their conditions in Eastern Europe. It is clear to those who have attended previous Crimea conferences that great progress has been and continues to be made. Nevertheless, there is a large measure of work to be done throughout the Former Soviet Union to standardize procedures, to enhance interlibrary cooperation, and to extend services to all citizens. Crimea ' 97 was a rewarding experience, both professionally and personally. It is indeed a fascinating experience to meet and to interact with people from a variety of countries and cultural orientations.

\section{(Faculty use conl. from page 553)}

made much progress in pooling Web expertise on campus, coordinating support, and providing a forum for sharing ideas about instructional use of the Web. Attenclance at workshops and brown bags is good, faculty are adding pages to the college's Wel server, and more classes are using the Web as a regular part of their work.

While it is too early to make any final assessment of the team's effectiveness in providing support to faculty, for the library; the team has already achieved its secondary goal of keeping librarians involved in campus Web activities. By serving as a central location for the teams's activities - workshops and brown bags are held in the library - the library is able to demonstrate its interest and involvement with the Web. By collaborating with other team members, librarians broaden their own Web skills. And, most important, by being under the aegis of the team, librarians' efforts to support the Web are now more visible and reach more people. 